\title{
INTERAÇÃO DE BACTÉRIAS FLUORESCENTES DO GÊNERO Pseudomonas E DE Bacillus spp. COM A RIZOSFERA DE DIFERENTES PLANTAS ${ }^{(1)}$
}

\author{
Luciana Fontes Coelho ${ }^{(2)}$, Sueli dos Santos Freitas ${ }^{(3)}$, Arlete Marchi \\ Tavares de Melo $^{(3)}$ \& Gláucia Maria Bovi Ambrosano ${ }^{(4)}$
}

\begin{abstract}
RESUMO
Embora haja muitos trabalhos na literatura com rizobactérias promotoras do crescimento de plantas (RPCPs), existem poucos que expliquem seu mecanismo de ação. É possível que algumas rizosferas favoreçam a colonização radicular por RPCPs, facilitando o estabelecimento da interação planta-bactéria, como se houvesse certa especificidade entre ambas. $O$ objetivo deste trabalho foi verificar se a rizosfera de alface, em comparação com a de outras espécies vegetais, favorece o estabelecimento de bactérias fluorescentes do gênero Pseudomonas, em comparação com as do gênero Bacillus. Coletaram-se amostras do sistema radicular de alface, rúcula, chicória, salsa e tiririca em oito propriedades de produtores comerciais de hortaliças, na região de Campinas, SP. Foi feita a contagem de Pseudomonas spp. fluorescentes e de Bacillus spp. por diluição em série e plaqueamento. De maneira geral, observou-se maior crescimento de Pseudomonas spp. fluorescentes na rizosfera de alface-crespa em relação à de outras plantas, mas isso não ocorreu com Bacillus spp.
\end{abstract}

Termos de indexação: especificidade, rizobactérias, alface, RPCPs.

\footnotetext{
(1) Parte da Tese de Mestrado da primeira autora apresentada ao Instituto Agronômico - IAC. Recebido para publicação em março de 2006 e aprovado em agosto de 2007.

${ }^{(2)}$ Mestranda de Pós-Graduação em Agricultura Tropical e Subtropical do Instituto Agronômico - IAC. Caixa Postal 28, CEP 13001970 Campinas (SP).

${ }^{(3)}$ Pesquisadora do IAC. E-mail: sfreitas@iac.sp.gov.br

${ }^{(4)}$ Professora da Faculdade de Odontologia, UNICAMP. Piracicaba (SP).
} 


\title{
SUMMARY: INTERACTION OF FLUORESCENT PSEUDOMONADS AND Bacillus spp. WITH DISTINCT PLANT RHIZOSPHERES
}

\begin{abstract}
Despite numerous reports on plant growth-promoting rhizobacteria (PGPR), there are few of them explaining their mode of action. It is possible that some plants promote bacterial colonization in the rhizosphere to facilitate plant-bacterium interaction, as if there were a certain mutual specificity. The objective of this study was to verify if lettuce plants promote root colonization by fluorescent pseudomonads, in comparison with other plants and with Bacillus spp. Roots of lettuce and some other vegetables were sampled in different properties of small commercial producers in Campinas-SP, Brazil. Colony forming units (cfu) of fluorescent pseudomonads and Bacillus spp. were counted by serial dilution and plating. The numbers of fluorescent pseudomonads were significantly higher in lettuce rhizosphere than in other plants, unlike the numbers of Bacillus spp.
\end{abstract}

Index terms: specificity; rhizobacteria; lettuce; PGPR.

\section{INTRODUÇÃO}

A produção de inoculantes de baixo custo com rizobactérias promotoras de crescimento de plantas (RPCPs) é uma alternativa para diminuir os riscos ambientais causados pela utilização inadequada - e às vezes excessiva - de insumos e agrotóxicos, aumentar a produção agrícola, tornar o produto mais competitivo e diferenciado e, ainda, diminuir os custos para o produtor.

As rizobactérias promotoras do crescimento de plantas (RPCPs) habitam a rizosfera - a região do solo sob influência das raízes. Entre os diversos mecanismos de ação já relatados para promover o crescimento de plantas estão a produção de hormônios de crescimento, como auxinas (Asghar et al., 2002), e a solubilização de fosfatos minerais (Freitas et al., 1997). Além disso, RPCPs são importantes agentes de controle biológico, pois podem suprimir microrganismos patogênicos da rizosfera, pela produção de ß-1,3-glucanase (Fridlender et al., 1993), antibióticos (Raaijmakers et al., 1997), ácido cianídrico (Owen \& Zdor, 2001) e sideróforos (Pidello, 2003). Sideróforos são compostos de baixo peso molecular, quelantes de ferro, produzidos pelas bactérias sob condições limitantes desse elemento (Neilands et al., 1984). A promoção de crescimento de plantas pela diminuição da incidência de doenças pode se dar pela inibição direta do crescimento do patógeno (Freitas \& Pizzinatto, 1997; Raaijmakers et al., 1997; Owen \& Zdor, 2001) e pela indução de resistência sistêmica (Fridlender et al., 1993; Nandakumar et al., 2001), entre outras maneiras.

Existem relatos da promoção de crescimento por rizobactérias em várias culturas, como trigo (Luz, 2001), plantas ornamentais (Yuen \& Schroth, 1986), alface (Freitas et al., 2003), citros (Freitas \& AguilarVildoso, 2004), árvores florestais (Garcia et al., 2004), entre outras. Nesses casos citados, a promoção de crescimento está ligada a vários fatores, como aumento na produção de grãos e no crescimento da planta, diminuição na incidência de patógenos ou na severidade da doença, antecipação da ida de mudas para o campo, além de outros. O efeito no crescimento da planta pode ser expresso tanto pela massa da matéria seca de parte aérea ou raízes, como pela altura.

No entanto, embora haja inúmeros relatos positivos sobre as RPCPs quanto ao aumento na produção das culturas, crescimento de plantas e supressão de doenças, a utilização desses microrganismos nem sempre tem fornecido bons resultados: um obstáculo a sua utilização comercial é que os isolados introduzidos podem ter dificuldade de se estabelecer e sobreviver em condições de campo (Atkinson \& Watson, 2000). Portanto, é necessário, primeiramente, estudar a ecologia desses microrganismos na rizosfera e obter informações sobre mecanismos de colonização de raízes, especificidade de hospedeiros, influência de fatores ambientais e interações com outros microrganismos.

Pela avaliação do número de bactérias na rizosfera de plantas é possível conhecer alguns dos fatores que exercem influência sobre seu estabelecimento em um ambiente e avaliar sua capacidade de se estabelecer na rizosfera. Como exemplo, Chanway et al. (2000) detectaram, pela enumeração periódica de rizobactérias promotoras do crescimento previamente marcadas com resistência a antibióticos e inoculadas em plântulas de abeto, que tanto isolados de Bacillus spp. quanto de Pseudomonas spp. do grupo fluorescente permaneceram na rizosfera por até 71 meses após a inoculação. Concluíram que havia interação entre o isolado e o local, mas não avaliaram quais dos fatores ambientais poderiam interferir nessa interação. Já Freitas et al. (2003) sugeriram que aspectos nutricionais do substrato em que se desenvolviam plantas de alface deveriam influenciar a capacidade de promoção do crescimento por bactérias fluorescentes do gênero Pseudomonas, justamente pela variação do efeito dos isolados bacterianos nos diversos substratos utilizados no estudo. A conclusão semelhante chegaram Freitas \& Aguilar-Vildoso (2004), também pela enumeração 
desse grupo bacteriano na rizosfera de plantas cítricas: os autores concluíram que Pseudomonas fluorescentes têm seu desenvolvimento influenciado pelo substrato e pelo ambiente em que se desenvolvem, particularmente pela rizosfera.

A alface foi utilizada porque, além de ser a hortaliça folhosa mais consumida pelos brasileiros, é sensível às condições adversas de temperatura, umidade e chuva, exigindo atenção especial quanto ao controle de pragas e doenças. A adoção da prática de inoculação de uma RPCP na cultura da alface seria uma forma de diminuir a dependência de produtos químicos sintéticos. Os produtos agrícolas conhecidos como orgânicos - isto é, aqueles em cuja produção a utilização de insumos é bastante limitada - vêm tendo demanda crescente, o que justifica estudos que possam facilitar o atendimento dessa demanda.

O objetivo deste trabalho foi verificar se a rizosfera de alface, em comparação com a de outras espécies vegetais, favorece o estabelecimento de bactérias fluorescentes do gênero Pseudomonas, em comparação com as do gênero Bacillus.

\section{MATERIAL E MÉTODOS}

Foram amostradas plantas adultas em oito propriedades agrícolas, em variadas condições de cultivo, no município de Campinas, Estado de São Paulo. Em todas as propriedades buscou-se coletar alface (Lactuca sativa) e mais duas espécies vegetais, cultivadas ou não. Nas propriedades Amarais, Matão, Santa Genebra, São Gonçalo e São José, o histórico é de cultivo contínuo com hortaliças folhosas. Nas propriedades Boa Esperança e Guará, os produtores relataram rotação de culturas com milho e milheto, respectivamente. Na propriedade São Marcos, antes do cultivo com alface havia sido cultivada couve por mais de 10 anos. No quadro 1 observam-se as espécies e quantidades de plantas coletadas e as bactérias quantificadas em cada propriedade. No quadro 2 são apresentadas as características químicas de seis solos amostrados, determinadas de acordo com o Sistema IAC de análise de solo (Raij et al., 2001). Em cada propriedade, retirou-se uma amostra composta do solo, de acordo com Ghini et al. (2006).

Quadro 1. Locais de amostragem, espécies e quantidades de plantas amostradas e grupos bacterianos quantificados

\begin{tabular}{|c|c|c|c|c|}
\hline \multirow{2}{*}{ Propriedade } & \multirow{2}{*}{ Espécie coletada ${ }^{(1)}$} & \multirow{2}{*}{$\mathrm{N}^{\circ}$ de plantas } & \multicolumn{2}{|c|}{ Bactérias quantificadas ${ }^{(2)}$} \\
\hline & & & Pseudomonas & Bacillus \\
\hline Amarais & $\begin{array}{l}\text { Alface-crespa 'Vera' } \\
\text { Rúcula 'Royal' } \\
\text { Chicória }\end{array}$ & $\begin{array}{l}10 \\
10 \\
10\end{array}$ & Sim & Sim \\
\hline Boa Esperança & $\begin{array}{l}\text { Alface-crespa 'Vera' } \\
\text { Rúcula } \\
\text { Salsa }\end{array}$ & $\begin{array}{l}10 \\
10 \\
10\end{array}$ & Sim & Não \\
\hline Guará & $\begin{array}{l}\text { Alface-crespa 'Vera' } \\
\text { Alface americana 'Lucy Brown' } \\
\text { Chicória }\end{array}$ & $\begin{array}{l}3 \\
3 \\
3\end{array}$ & Sim & Sim \\
\hline Matão & $\begin{array}{l}\text { Alface-crespa 'Vera' } \\
\text { Rúcula } \\
\text { Salsa }\end{array}$ & $\begin{array}{l}10 \\
10 \\
10\end{array}$ & Sim & Não \\
\hline Santa Genebra & $\begin{array}{l}\text { Alface-crespa 'Vera' } \\
\text { Rúcula } \\
\text { Salsa }\end{array}$ & $\begin{array}{l}10 \\
10 \\
10\end{array}$ & Sim & Sim \\
\hline São Gonçalo & $\begin{array}{l}\text { Alface-crespa 'Vera' } \\
\text { Rúcula } \\
\text { Salsa }\end{array}$ & $\begin{array}{l}10 \\
10 \\
10\end{array}$ & Sim & Sim \\
\hline São José & $\begin{array}{l}\text { Alface-crespa 'Vera' } \\
\text { Chicória 'Eros' } \\
\text { Salsa }\end{array}$ & $\begin{array}{l}10 \\
10 \\
10\end{array}$ & Sim & Sim \\
\hline São Marcos & $\begin{array}{l}\text { Alface-crespa 'Vera' } \\
\text { Alface americana 'Lucy Brown' } \\
\text { Tiririca }\end{array}$ & $\begin{array}{l}3 \\
3 \\
3\end{array}$ & Sim & Sim \\
\hline
\end{tabular}

(1) Nomes científicos: alface: Lactuca sativa; chicória: Cicorium endivia; rúcula: Eruca sativa; salsa: Petrosolium sativum; tiririca: Cyperus rotundus. ${ }^{(2)}$ Grupos bacterianos: bactérias fluorescentes dos gêneros Pseudomonas e Bacillus spp. 
Quadro 2. Características químicas dos solos $\operatorname{amostrados}^{(1)}$

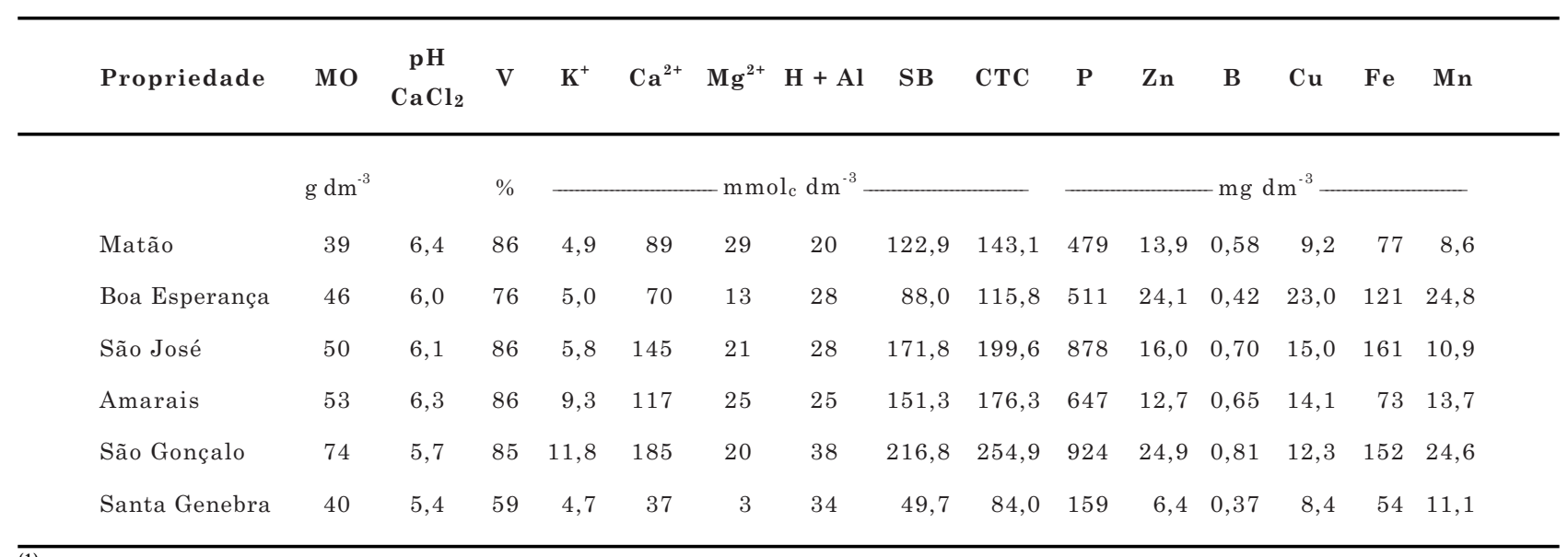

(1) Análise pelo Sistema IAC de análise de solo (Raij et al., 2001).

As plantas foram retiradas com um pouco de solo aderido às raízes, colocadas em sacos plásticos identificados e levadas ao laboratório para se proceder às contagens de dois grupos bacterianos específicos. Contaram-se, por diluição em série, as bactérias do grupo fluorescente do gênero Pseudomonas e as bactérias do gênero Bacillus, em placas com meio B de King et al. (1954) e BDA (batata, 200 g; dextrose, $20 \mathrm{~g}$; ágar, 20 g e água qsp, $1 \mathrm{~L}$ ), respectivamente.

Cada amostra coletada constituiu-se de uma raiz inteira, que foi separada da planta, agitada vigorosamente para desprender o solo que estava mais frouxamente aderido e colocada em frasco de erlenmeyer com solução salina esterilizada (solução de $\mathrm{MgSO}_{4} \cdot 7 \mathrm{H}_{2} \mathrm{O}$ 0,01 M). O conjunto raiz + solo que permaneceu aderido foi considerado ambiente rizosférico. Esse conjunto, dentro do frasco de erlenmeyer, foi submetido a 30 minutos de agitação, em agitador mecânico. Em seguida, prepararam-se diluições em série de fator 10 a partir da suspensão do interior do frasco. As raízes foram secas até massa constante em estufa a $62{ }^{\circ} \mathrm{C}$, para permitir a quantificação das bactérias presentes nas raízes secas (ufcs $\mathrm{g}^{-1}$ ).

Para contagem de bactérias do grupo fluorescente do gênero Pseudomonas, alíquotas de $0,1 \mathrm{~mL}$ de cada diluição foram transferidas para placas de Petri com meio de cultura B de King et al. (1954) e espalhadas com o auxílio da alça de Drigalski, em duplicata. As placas foram mantidas a $28-30{ }^{\circ} \mathrm{C}$ por $24 \mathrm{~h}$. Contaram-se como bactérias do grupo fluorescente do gênero Pseudomonas as colônias que fluoresceram sob luz com comprimento de onda próximo do ultravioleta (King et al., 1954).

O procedimento utilizado para quantificação de Bacillus spp. foi semelhante ao descrito anteriormente, só que a suspensão de solo anteriormente obtida pela agitação do conjunto raízes + solo - e utilizada para contagem de Pseudomonas fluorescentes - foi colocada em banho-maria a $80^{\circ} \mathrm{C}$ por $20 \mathrm{~min}$, antes de se prepararem novas diluições em série. A contagem das colônias que cresceram em meio de cultura BDA foi feita após incubação a $28^{\circ} \mathrm{C}$ por $48 \mathrm{~h}$ (Bettiol, 1995).

As bactérias fluorescentes do gênero Pseudomonas foram quantificadas nas raízes das plantas colhidas em todas as oito propriedades. Já as do gênero Bacillus foram quantificadas em seis propriedades (Quadro 1).

Para análise estatística, os dados foram transformados em $\log \mathrm{x}$ e $\log (\mathrm{x}+1)$ e utilizou-se $\mathrm{o}$ teste de Tukey a $5 \%$ para comparação das médias. Com os dados obtidos em quatro propriedades, foi feita análise conjunta dos dados de contagem de Pseudomonas spp. fluorescentes, porque nesses locais se coletaram as mesmas espécies de plantas.

\section{RESULTADOS E DISCUSSÃO}

Nas propriedades cujos dados foram analisados conjuntamente - Boa Esperança, Matão, Santa Genebra e São Gonçalo - observou-se maior número de Pseudomonas spp. fluorescentes na rizosfera de alface-crespa, em comparação com as rizosferas de rúcula e salsa. Dentre essas três, a rizosfera de salsa foi a que apresentou menor número de Pseudomonas spp. fluorescentes, como mostrado pela figura 1 .

Nas propriedades Guará e São Marcos compararamse os números de Pseudomonas spp. fluorescentes das rizosferas de duas variedades da mesma espécie, alfacecrespa e alface-americana, que não diferiram entre si (Quadro 3). Todavia, quando se compararam chicória e alface-americana - espécies da mesma família, coletadas na propriedade Guará - observou-se que havia em suas raízes quantidades significativamente 
diferentes de Pseudomonas spp. fluorescentes (Quadro 3). Embora essas plantas pertençam à mesma família, devem ter liberado exsudatos qualitativa e quantitativamente diferentes, influenciando os números dessas bactérias. A diferença entre as exsudações radiculares pode explicar também os números de Pseudomonas spp. fluorescentes significativamente diferentes entre alface, principalmente a americana, e salsa e tiririca,

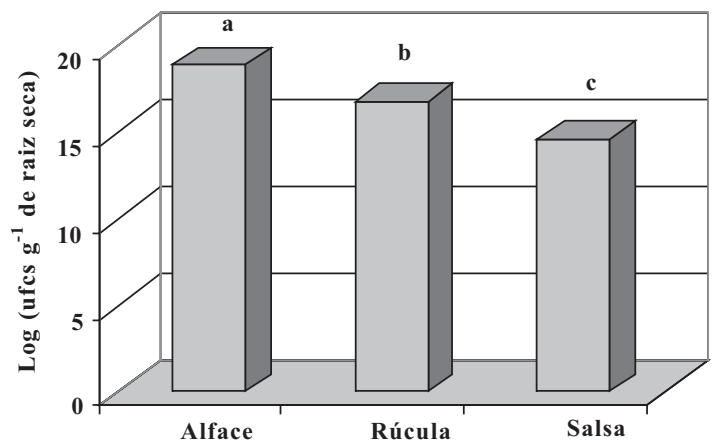

Figura 1. Número de Pseudomonas spp. fluorescentes na rizosfera de alface, rúcula e salsa, em quatro locais: Matão, Boa Esperança, São Gonçalo e Santa Genebra. Média de 10 repetições; coeficiente de variação $=9,63 \%$. Colunas seguidas de letras diferentes diferem entre si a $5 \%$ pelo teste de Tukey. ufcs: unidades formadoras de colônias.

Quadro 3. Número de bactérias fluorescentes do gênero Pseudomonas nas rizosferas de diferentes espécies, em quatro locais coletadas nas propriedades São Marcos e São José (Quadro 3). De fato, as plantas podem exsudar muitos componentes, principalmente na forma de aminoácidos, ácidos orgânicos e açúcares (Lynch \& Whipps, 1990), que são os maiores responsáveis pelo crescimento e pela atividade dos microrganismos na rizosfera. Sabe-se que a exsudação radicular intermedeia, por sinais moleculares, o reconhecimento entre plantas e microrganismos, com efeitos tanto sobre a microbiota benéfica quanto sobre a patogênica às primeiras (Bais et al., 2006). Considerando-se a especificidade do reconhecimento por sinais moleculares, é claro que espécies vegetais diferentes têm padrões diferentes de exsudação (George et al., 2002; Sandnes et al., 2005).

Com relação a Bacillus spp., as diferenças de número de ufcs entre as rizosferas foram menos marcantes (Quadro 4). Nas propriedades Guará e São Marcos não houve diferenças significativas dos números dessas bactérias entre as rizosferas avaliadas; na primeira propriedade, as plantas coletadas foram alface lisa, alface-americana e chicória e, na segunda, alface lisa, alface-americana e tiririca. Embora a tiririca seja de uma família distante das outras plantas com as quais se fez a comparação, a rizosfera de nenhuma das espécies resultou em diferenças entre os números de Bacillus spp. Nas outras propriedades, de maneira geral, o número de bactérias do gênero Bacillus foi significativamente maior em alface, às vezes igualando-se ao número em chicória ou em rúcula (Quadro 4).
Espécie vegetal

Propriedade

Amarais ${ }^{(1)}$

Alface-crespa

Chicória

Rúcula

Guará(2)

Alface-americana

Chicória

São José(1)

Alface-crespa

Chicória

Salsa

São $\operatorname{Marcos}^{(2)}$
Alface-americana
Alface-crespa
Tiririca

$\begin{array}{ll} & \text { Chicória } \\ & \text { Salsa } \\ \text { São } \operatorname{Marcos}^{(2)} & \text { Alface-americana } \\ & \text { Alface-crespa } \\ & \text { Tiririca }\end{array}$

Pseudomonas spp. fluorescentes

ufcs $10^{7} \mathrm{~g}^{-1}$ de raízes secas

$\begin{array}{ll}17,8 \mathrm{a} & 3,5 \\ 4,0 \mathrm{~b} & \\ 4,8 \mathrm{~b} & \\ 26,3 \mathrm{a} & \\ 8,0 \mathrm{ab} & \\ 3,0 \mathrm{~b} & \\ 6,0 \mathrm{a} & \\ 5,0 \mathrm{a} & \\ 1,7 \mathrm{~b} & \\ 4,0 \mathrm{a} & \\ 0,9 \mathrm{ab} & \\ 0,1 \mathrm{~b} & \end{array}$

\footnotetext{
${ }^{(1)}$ Médias de 10 repetições. ${ }^{(2)}$ Médias de três repetições. Médias seguidas pelas mesmas letras não diferem entre si a 5 \% pelo teste de Tukey. Dados originais, transformados em $\log (x+1)$ para análise de variância.
} 
Quadro 4. Número de Bacillus spp. provenientes das rizosferas de diferentes plantas, em seis locais

\begin{tabular}{|c|c|c|c|}
\hline Local & Cultura & Bacillus spp. & CV \\
\hline & & ufcs $x 10^{6} \cdot \mathrm{g}^{-1}$ de raízes secas & $\%$ \\
\hline \multirow[t]{3}{*}{ Amarais ${ }^{(1)}$} & Alface & $370 \mathrm{a}$ & 3,6 \\
\hline & Chicória & $192 \mathrm{ab}$ & \\
\hline & Rúcula & $170 \mathrm{~b}$ & \\
\hline \multirow[t]{3}{*}{ Guará(2) } & Alface & $1222 \mathrm{a}$ & 6,3 \\
\hline & Alface-americana & $1530 \mathrm{a}$ & \\
\hline & Chicória & $160 \mathrm{a}$ & \\
\hline \multirow[t]{3}{*}{ Santa Genebra(1) } & Alface & $76 \mathrm{a}$ & 17,7 \\
\hline & Rúcula & $46 \mathrm{a}$ & \\
\hline & Salsa & $11 \mathrm{~b}$ & \\
\hline \multirow[t]{3}{*}{ São Gonçalo(1) } & Alface & $96 \mathrm{a}$ & 5,7 \\
\hline & Rúcula & $22 \mathrm{~b}$ & \\
\hline & Salsa & $3 \mathrm{c}$ & \\
\hline \multirow[t]{3}{*}{ São José(1') } & Alface & $25 \mathrm{a}$ & 5,8 \\
\hline & Chicória & $31 \mathrm{a}$ & \\
\hline & Salsa & $4 \mathrm{~b}$ & \\
\hline \multirow[t]{3}{*}{ São $\operatorname{Marcos}^{(2)}$} & Alface & $3 \mathrm{a}$ & 2,8 \\
\hline & Alface-americana & $5 \mathrm{a}$ & \\
\hline & Tiririca & $3 a$ & \\
\hline
\end{tabular}

\footnotetext{
${ }^{(1)}$ Média de 10 repetições. ${ }^{(2)}$ Média de três repetições. Médias seguidas pelas mesmas letras não diferem entre si a $5 \%$ pelo teste
} de Tukey. Dados originais, transformados em log $(x+1)$ para a análise de variância.

De maneira geral, o que de mais marcante se nota nos dados apresentados no quadro 3 e na figura 1 é o fato de que o número de bactérias fluorescentes do gênero Pseudomonas foi maior na rizosfera de alface - crespa ou americana - do que na das outras plantas. Em outras palavras, observou-se favorecimento de Pseudomonas spp. fluorescentes na rizosfera de alface em relação à rizosfera das outras plantas estudadas. Esse efeito da rizosfera foi observado independentemente das características do solo ou das condições de cultivo, diferentes em cada propriedade. Uma das hipóteses é de que a rizosfera de alface, independentemente do ambiente, produza alguma substância benéfica a essas bactérias, composto esse ausente ou produzido em quantidade muito menor na rizosfera das outras plantas. Muitos autores consideram a influência da exsudação radicular sobre os números de rizobactérias na rizosfera (Miller et al., 1989; ClaysJosserand et al., 1995; Lemanceau et al., 1995; Latour et al., 1996; Kravchenko et al., 2003; Freitas \& Aguilar-Vildoso, 2004; Bais et al., 2004). Pelas variações na exsudação radicular, diferentes espécies de plantas que crescem no mesmo tipo de solo selecionam comunidades diversas de bactérias (Wieland et al., 2001; Kowalchuk et al., 2002).
Para Bacillus spp. também houve certo favorecimento da rizosfera de alface em relação às outras plantas, ainda que não tão acentuado quanto o que se observou em Pseudomonas. Esse favorecimento poderia levantar a hipótese de especificidade entre Pseudomonas fluorescentes e alface, de maneira semelhante ao trabalho de Glandorf et al. (1993). Assim como no artigo citado, neste também não há subsídios para afirmar que haja especificidade entre Pseudomonas e alface, mas, em duas propriedades Guará e São Marcos - os números de Pseudomonas spp. foram diferentes entre as rizosferas, enquanto os de Bacillus spp. não o foram. Em Amarais, os números de Pseudomonas spp. em alface foram superiores aos das outras rizosferas; já os de Bacillus spp. diferiram apenas entre alface e rúcula, mas não entre chicória e alface ou entre chicória e rúcula. Somente em São José os números de ambos os grupos bacterianos comportaram-se semelhantemente em relação às rizosferas. É possível que a planta de alface produza exsudatos que estimulem o crescimento bacteriano como um todo, o que não exclui, ainda assim, a hipótese de que isolados de Pseudomonas spp. fluorescentes sejam favorecidos pela rizosfera de alface. Pode ocorrer especificidade de RPCPs em relação a cultivares, às 
espécies propriamente ditas ou, simplesmente, não haver especificidade quanto à colonização de raízes (Miller et al., 1989; Fromin et al., 2001).

A análise química dos solos revelou diferenças entre eles, mas não foi feita tentativa de verificar se essas diferenças, especificamente, foram as responsáveis pelos variados resultados. Embora a influência do solo não tenha sido avaliada neste estudo - pelo menos diretamente, porque não era esse o objetivo -, sabe-se que esse fator, juntamente com a planta, é um dos principais responsáveis pela diversidade da comunidade de bactérias rizosféricas (Chiarini et al., 1998). Mais estudos são necessários para determinar como as características dos solos interferem na seleção de bactérias pela planta hospedeira.

Independentemente disso, o favorecimento de um gênero de bactéria em uma determinada rizosfera é uma importante característica, que pode determinar o sucesso de um eventual inoculante bacteriano (Atkinson \& Watson, 2000). Os resultados relatados aqui permitem concluir que a rizosfera de alface favorece o desenvolvimento de bactérias fluorescentes do gênero Pseudomonas. Essa característica pode ser decisiva na produção de inoculantes comerciais.

\section{CONCLUSÕES}

1. Houve favorecimento ao crescimento de $P$ seudomonas spp. fluorescentes na rizosfera de alface, em relação à das outras plantas estudadas.

2. O desenvolvimento de Pseudomonas spp. fluorescentes foi influenciado pelo tipo de planta.

3. Com relação a Bacillus spp., não se observou o mesmo favorecimento verificado para Pseudomonas spp. fluorescentes; em alguns casos, o número dessas bactérias na rizosfera de alface igualou-se ao de chicória ou rúcula.

\section{LITERATURA CITADA}

ASGHAR, H.N.; ZAHIR, Z.A.; ARSHAD, M \& KHALIQ, A. Relationship between in vitro production of auxins by rhizobacteria and their growth-promoting activities in Brassica juncea L. Biol. Fert. Soils, 35:231-237, 2002.

ATKINSON, D.C. \& WATSON, A. The beneficial rhizosphere: A dynamic entity. Appl. Soil Ecol., 15:99-104, 2000.

BAIS, H.P.; PARK, S.W.; WEIR, T.L; CALLAWAY, R.M. \& VIVANCO, J.M. How plants communicate using the underground information superhighway. Trends Plant Sci., 9:26-32, 2004.

BAIS, H.P.; WEIR, T.L.; PERRY, L.G.; GILROY, S. \& VIVANCO, J.M. The role of root exsudation in rhizosphere interactions with plants and other organisms. Ann. Rev. Plant Biol., 57:233-256, 2006.
BETTIOL, W. Isolamento seletivo de Bacillus. In: MELO, I.S. \& SANHUEZA, R.M.V., coords. Métodos de seleção de microrganismos antagônicos a fitopatógenos. Jaguariúna, Embrapa-CNPMA, 1995. p.35-36. (Manual Técnico)

CHANWAY, C.P.; SHISHIDO, M.; NAIRN, J.; JUNGWIRTH, S.; MARKHAM, J.; XIAO, G. \& HOLL, F.G. Endophytic colonization and field responses of hybrid spruce seedlings after inoculation with plant growth-promoting rhizobacteria. For. Ecol. Manag., 133:81-88, 2000.

CHIARINI, L.; BEVIVINO, A.; DALMASTRI, C.; NACAMULLI, C. \& TABACCHIONI, S. Influence of plant development, cultivar and soil type on microbial colonization of maize roots. Appl. Soil Ecol., 8:11-18, 1998.

CLAYS-JOSSERAND, A.; LEMANCEAU, P.; PHILIPPOT, L. \& LENSI, R. Influence of two plant species (flax and tomato) on the distribution of nitrogen dissimilative abilities within fluorescent Pseudomonas spp. Appl. Environ. Microbiol., 61:1745-1749, 1995.

FREITAS, J.R.; BANERJEE, M.R. \& GERMIDA, J.J. Phosphate-solubilizing rhizobacteria enhance the growth and yield but not phosphorus uptake of canola (Brassica napus L.). Biol. Fert. Soils, 24:358-364, 1997.

FREITAS, S.S. \& AGUILAR-VILDOSO, C.I. Rizobactérias e promoção do crescimento de plantas cítricas. R. Bras. Ci. Solo, 28:987-994, 2004.

FREITAS, S.S.; MELO, A.M.T. \& DONZELI, V.P. Promoção de crescimento de alface por rizobactérias. R. Bras. Ci. Solo, 27:61-70, 2003.

FRIDLENDER, M.; INBAR, J. \& CHET, I. Biological control of soilborne plant pathogens by a B-1,3-glucanase-producing Pseudomonas cepacia. Soil Biol. Biochem., 25:1211$1221,1993$.

FROMIN, N.; ACHOUAK, W.; THIÉRY, J.M. \& HEULIN, T. The genotypic diversity of Pseudomonas brassicacearum populations isolated from roots of Arabidopsis thaliana: Influence of plant genotype. FEMS Microbiol. Ecol., 37:21$29,2001$.

GARCIA, J.A.L.; DOMENECH, J.; SANTAMARIA, C.; CAMACHO, M.; DAZA, A. \& MAÑERO, F.J.G. Growth of forest plants (pine and holm-oak) inoculated with rhizobacteria: Relationship with microbial community structure and biological activity of its rhizosphere. Environ. Exper. Bot., 52:239-251, 2004.

GEORGE, T.S.; GREGORY, P.J.; WOOD, M.; READ, D. \& BURESH, R.J. Phosphatase activity and organic acids in the rhizosphere of potential agroforestry species and maize. Soil Biol. Biochem., 34:1487-1494, 2002.

GHINI, R.; FREITAS, S.S. \& OLIVEIRA, A.R. Amostragem de solo para análises biológicas. In: FILIZOLA, H.F.; GOMES, M.A.F. \& SOUZA, M.D., orgs. Manual de procedimentos de coleta de amostras em áreas agrícolas para análise da qualidade ambiental: Solo, água e sedimentos. Jaguariúna, Embrapa Meio Ambiente, 2006. v.1. p.57-79.

GLANDORF, D.C.M.; PETERS, L.G.L.; van der SLUIS, I.; BAKKER, P.A.H.M. \& SCHIPPERS, B. Crop specificity of rhizosphere pseudomonads and the involvement of root agglutinins. Soil Biol. Biochem., 25:981-989, 1993. 
KING, E.O.; WARD, M.K. \& RANEY, D.E. Two simple media for the demonstration of pyocyanin and fluorescin. J. Lab. Clinical Med., 44:301-307, 1954.

KOWALCHUK, G.A.; BUMA, D.S.; DE BOER, W.; KLINKHAMER, P.G.L. \& van VEEN, J.A. Effects of above-ground plant species composition and diversity on the diversity of soilborne microorganisms. Antonie Leeuwenhoek, 81:509-521, 2002.

KRAVCHENKO, L.V.; AZAROVA, T.S.; LEONOVA-ERKO, E.I.; SHAPOSHNIKOV, A.I.; MAKAROVA, N.M. \& TIKHONOVICH, I.A. Root exudates of tomato plants and their effect on the growth and antifungal activity of Pseudomonas Strains. Microbiol., 72:37-41, 2003.

LATOUR, X.; CORBERAND, T.; LAGUERRE, G.; ALLARD, F. \& LEMANCEAU, P. The composition of fluorescent pseudomonad populations associated with roots is influenced by plant and soil type. Appl. Environ. Microbiol., 62:2449-2456, 1996.

LEMANCEAU, P.; CORBERAND, T.; GARDAN, L.; LATOUR, X.; LAGUERRE, G.; BOEUFGRAS, J.M. \& ALABOUVETTE, C. Effect of two plant species, flax (Linum usitatissinum L.) and tomato (Lycopersicon esculentum Mill.), on the diversity of soilborne populations of fluorescent pseudomonads. Appl. Environ. Microbiol., 61:1004-1012, 1995

LUZ, W.C. Evaluation of plant growth-promoting and bioprotecting rhizobacteria on wheat crop. Fitopatol. Bras., 26:3, 2001.

LYNCH, J.M. \& WHIPPS, J.M. Substrate flow in the rhizosphere. Plant Soil, 129:1-10, 1990.

MILLER, H.J.; HENKEN, G. \& van VEEN, J.A. Variation and composition of bacterial population in the rhizosphere of maize, wheat, and grass cultivars. Can. J. Microbiol., 35:656-660, 1989.
NANDAKUMAR, R; BABU, S.; VISWANATHAN, R.; RAGUCHANDER, T. \& SAMIYAPPAN, R. Indution of systemic resistance in rice against sheath blight disease by Pseudomonas fluorescens. Soil Biol. Biochem., 33:603612, 2001.

NEILANDS, J.B. Siderophores of bacteria and fungi. Microbiol. Sci., 1:9-14, 1984.

OWEN, A. \& ZDOR, R. Effect of cyanogenic rhizobacteria on the growth of velvetleaf (Abutilon theophrasti) and corn (Zea mays) in autoclaved soil and the influence of supplemental glycine. Soil Biol. Biochem., 33:801-809, 2001.

PIDELLO, A. The effect of Pseudomonas fluorescens strains varying in pyoverdine production on the soil redox status. Plant Soil, 253:373-379, 2003.

RAAIJMAKERS, J.M.; WELLER, D.M. \& THOMASHOW, L.S. Frequency of antibiotic-producing Pseudomonas spp. in natural environments. Appl. Environ. Microbiol., 63:881887, 1997.

RAIJ, B. van; ANDRADE, J.C.; CANTARELLA, H. \& QUAGGIO, J.A. Análise química para avaliação da fertilidade de solos tropicais. Campinas, Instituto Agronômico, 2001. 285p.

SANDNES, A.; ELDHUSET, T.D. \& WOLLEB $\& K$, G. Organic acids in root exudates and soil solution of Norway spruce and silver birch. Soil Biol. Biochem., 37:259-269, 2005.

WIELAND, G.; NEUMANN, R. \& BACKHAUS, H. Variation of microbial communities in soil, rhizosphere, and rhizoplane in response to crop species, soil type, and crop development. Appl. Environ. Microbiol., 67:5849-5854, 2001.

YUEN, G.Y. \& SCHROTH, M.N. Interactions of Pseudomonas fluorescens strain E6 with ornamental plants and its effect on the composition of root-colonizing microflora. Phytopathology, 76:176-180, 1986. 